Article

\title{
First-Year University Students Who Self-Select into Health Studies Have More Desirable Health Measures and Behaviors at Baseline but Experience Similar Changes Compared to Non-Self-Selected Students
}

\author{
Mary-Jon Ludy ${ }^{1}$, Abigail P. Crum ${ }^{1}$, Carmen A. Young ${ }^{2}{ }^{\mathbb{1}}$, Amy L. Morgan ${ }^{3}$ and \\ Robin M. Tucker ${ }^{4, *}$ \\ 1 Department of Public \& Allied Health, Bowling Green State University, Health \& Human Services, \\ Bowling Green, OH 43403, USA; mludy@bgsu.edu (M.-J.L.); apcrum@bgsu.edu (A.P.C.) \\ 2 Department of Athletics, Rutgers University, 1 Scarlet Knight Way, Piscataway, NJ 08854, USA; \\ cyoung@scarletknights.com \\ 3 School of Human Movement, Sport, \& Leisure Studies, Bowling Green State University, 216 Eppler South, \\ Bowling Green, OH 43403, USA; amorgan@bgsu.edu \\ 4 Department of Food Science and Human Nutrition, Michigan State University, 2110 S. Anthony Hall, \\ 474 S. Shaw Ln, East Lansing, MI 48824, USA \\ * Correspondence: tucker98@msu.edu; Tel.: +1-517-353-3408
}

Received: 28 December 2017; Accepted: 14 March 2018; Published: 16 March 2018

\begin{abstract}
Studies demonstrate that first-year university students are at high risk for weight gain. These reports typically rely on self-selected participants. The purpose of this study was to explore if students who chose to participate in a health-based research study had more desirable health measures and behaviors than students who completed health assessments as part of a first-year seminar course. Health measures included blood pressure (BP), body mass index (BMI), and percent body fat. Health behaviors included dietary patterns (Starting the Conversation questionnaire) and alcohol use (Alcohol Use Disorders Identification Test-Consumption). A total of 191 (77\% female) participants completed testing in the self-selected "Health Study" group, whereas 73 of the 91 students ( $80 \%, 55 \%$ female) enrolled in the "Seminar" allowed their data to be used for research purposes. Baseline measures favored Health Study participants, including but not limited to fewer participants with undesirable BMI ( $\geq 25.0 \mathrm{~kg} / \mathrm{m}^{2}$; males and females) and a smaller percentage of participants with undesirable BP (systolic $\geq 120 \mathrm{mmHg}$ and/or diastolic $\geq 80 \mathrm{mmHg}$; females only). Differences in dietary behaviors at baseline were inconsistent, but Seminar students engaged in more problematic alcohol-use behaviors. While both groups experienced undesirable changes in health measures over time, the degree of change did not differ between groups. Changes in health behaviors over time typically resulted in undesirable changes in the Seminar group, but the magnitude of change over time did not differ between groups. Thus, results from first-year university students who self-select into health studies likely underestimate the seriousness of undesirable health measures and behaviors but may accurately reflect the degree of change over time.
\end{abstract}

Keywords: alcohol; BMI; college health; college students; diet; health behaviors; risk assessment; self-selection; weight gain; young adults

\section{Introduction}

Numerous studies suggest that first-year university students are at high risk for weight gain (recently reviewed by [1,2]). Meta-analyses conclude that weight gain during the first year of university 
is approximately $1.6-1.8 \mathrm{~kg}[1,2]$. These estimates agree with another large-scale study of self-reported weight gain, where female first-year students reported gaining $1.4 \mathrm{~kg}$ and males reported gaining $1.6 \mathrm{~kg}(N=4687)$ [3]. Further, other studies indicate that weight gain can occur early in the first year, even during the first semester [4,5]. While gains are typically highest in the first year [6,7], this weight gain continues throughout the university experience [1,6-9], and those who enter their first year of university already overweight or obese are at higher risk for developing chronic diseases than their lean counterparts [10]. Even more concerning, it could be the case that these reports underestimate the negative health outcomes associated with the university experience due to self-selection bias.

Since participation is typically voluntary in studies measuring weight and health changes among university students, participant self-selection by healthier individuals could pose a problem [11-14]. Self-selection bias hampers the generalizability of reported findings to the larger population of interest-regardless of sample size-because the study population differs systematically from the group it is meant to represent [15-17]. It could be that students who choose to participate in longitudinal investigations related to weight and health changes do not represent the larger population of university students, as participants may be more knowledgeable about and engaged in positive health behaviors. If this is the case, it is likely that weight and fat gains are higher among the general population of university students given previous work that suggests individuals with higher measures of adiposity are more likely to choose not to participate in or to drop out of health studies [18-20].

Alternatively, there could be reasons other than an interest in personal health that motivate university students to participate in research studies on this topic. Students new to campus might be interested in participating in a research study because they can earn credit for a class [21,22], help society [23], or because of financial incentives [24,25]. In the case of financial incentives, a number of studies suggest that payment was a leading factor in participants deciding to take part in a health study (reviewed by [26]). If such factors are more salient motivators for study involvement than health-related interests, these participants might not be substantively different from their peers in terms of general health measures.

The purpose of this study was to explore whether first-year students who chose to participate in a health-based research study had more desirable health measures and behaviors than students who completed health assessments as part of a first-year seminar course at both the beginning of the academic year (August) and at the end of the first semester (December) and to assess the degree of change over time between the two groups. We hypothesized that self-selected health study participants would have more desirable health measures (blood pressure (BP), body mass index (BMI), percent body fat $(\% \mathrm{BF})$ ), engage in fewer negative health behaviors (unhealthy diet and alcohol use patterns), and that these participants would experience undesirable changes in these parameters to a lesser degree over time than participants in a seminar course.

\section{Materials and Methods}

\subsection{Study Design}

Participants for this study were recruited from two pools. First, students who had an interest in participating in an on-going (Fall 2012-Fall 2015) study examining health and health behaviors among first-year university students (Health Study) were recruited through informational flyers, emails, and social media. Participation required contacting the researchers, making an appointment, and reporting to the laboratory at the beginning and end of the semester in which they participated in the study. Participants were compensated $\$ 5$ in campus cash or a spirit item (e.g., water bottle or t-shirt) at each visit. Informed consent was obtained prior to study participation. The second pool of students completed required health assessments as part of a graded 1-credit hour seminar course designed to assist with the transition to university during their first semester (Fall 2016) and chose to share their data for research purposes (Seminar). Sharing of the data was voluntary, and participation had no effect on the course grade; researchers did not know who consented until after grades were submitted. 
Seminar students were enrolled in the course by academic advisors during summer orientation. Any first-year student who did not have an introductory course in the major (e.g., "Introduction to Education" or "Introduction to the Social Work Profession") had the choice of signing up for one of 60 first-year seminar courses focused on a wide-range of topics. Five of these courses participated in health assessments and were included in the Seminar group (i.e., one section each of "Fight, Flight, or Freeze: The Impact of Stress", "Freshman Wilderness Experience", "MythBusters: Falcon Edition", and two sections of "Live Well, Learn Well"). Among Seminar participants, informed consent was obtained in class near the end of the semester (week 12), which allowed for data collected as part of the course assignments (both in weeks 2-3 and in weeks 14-15) to be used for research purposes. These results were then compared to data collected from Health Study participants. Seminar students were not compensated for their participation. Study participants were not able to participate in both groups. The Bowling Green State University Institutional Review Board (Health Study: Project 342745, Approved June 23, 2012; Seminar: Project 936799, Approved August 18, 2016) approved both studies.

\subsection{Measures}

All measures were taken at baseline (second or third week of the semester) and at follow-up (14th or 15th week of the semester). Health measures included BP measured by an automated blood pressure cuff (Omron 5 Series, Omron Corporation, Kyoto, Japan), BMI calculated from measured height and weight, and \%BF measured using bioelectrical impedance analysis (InBody 230; BioSpace, Seoul, Korea). Starting the Conversation (STC, a validated food frequency questionnaire) was used to assess changes in dietary behaviors [27]. The STC questionnaire includes eight questions regarding the intake of various types of foods over the past few months. The sum of the answers to these questions (each scored $0=$ most, $2=$ least healthful) provides a total diet quality score. A lower score indicates a more healthful diet (minimum $=0$, maximum $=16$ ) [27]. The STC questionnaire has successfully been used to identify changes in dietary patterns over a four-month period [27] (including with college students [28,29]), making it a useful measure of dietary behaviors in this timeframe and population. The Alcohol Use Disorders Identification Test-Consumption (AUDIT-C) was used to screen participants for heavy drinking or alcohol abuse [30]. The AUDIT-C has demonstrated excellent sensitivity in identifying heavy drinking as well as active alcohol dependence, and has been validated in college students [31]. The AUDIT-C consists of three questions, each scored $0=$ least, $4=$ most risky. The sum of the answers (minimum $=0$, maximum $=12$ ) provides a total risk score, with scores of 4 or more for males, and 3 or more for females, considered potentially hazardous [30].

\subsection{Statistical Analysis}

Paired sample $t$-tests, independent sample $t$-tests, Pearson's Chi-square, Mann-Whitney U, and Wilcoxon Signed-Rank tests were used to compare changes over time and differences between groups. Analyses were completed using IBM SPSS Statistics, Version 24 (Armonk, New York, NY, USA). Results are presented as means \pm standard error. The criterion for statistical significance in the data was $p<0.05$, two tailed.

\section{Results}

A total of 191 participants (age: $18.1 \pm 0.4$ years) completed testing in the Health Study group, while 73 (age: $18.4 \pm 0.5$ years) of the 91 students $(80 \%)$ in the Seminar group completed testing and also provided consent. In the Health Study group, 148 (77\%) participants were female, while among the Seminar group, 40 (55\%) were female. The sex distributions differed between studies $\left(\chi^{2}=11.806\right.$, $p=0.001)$. Because of this difference and because sex differences have been reported for a variety of the measures of interest (e.g., \%BF [32], body weight [33], or BP [34]), results from each study are presented by sex. A total of $30.2 \%$ of male Health Study participants indicated majoring in a health-related field (e.g., psychology, pre-nursing, dance) compared to $18.2 \%$ of male Seminar participants. Among females, $48.0 \%$ of Health Study and $48.8 \%$ of Seminar participants indicated majoring in a health-related field. 
The percentage of health-related majors did not differ between the groups ( $p>0.05$ for both). Sample sizes are provided in the tables and text and differ slightly among Seminar participants because several participants chose not to answer diet and alcohol questions.

\subsection{Differences in Health Measures}

In order to address the research question "do students who self-selected to participate in a health-based research study have more desirable health measures and health behaviors than students who completed health assessments as part of a first-year seminar course?", baseline data between each study group were compared. In terms of health measures at baseline (Table 1), compared to males in the Health Study, diastolic BP was higher in male Seminar students $(p=0.006)$, while both systolic $\mathrm{BP}(p=0.017)$ and diastolic BP $(p<0.001)$ were higher in female Seminar students. The percentage of Seminar participants who had undesirable BP (systolic $\geq 120 \mathrm{mmHg}$ and/or diastolic $\geq 80 \mathrm{mmHg}$ ) was higher than Health Study participants for both males $(p=0.026)$ and females $(p<0.001)$. Female Seminar students weighed more than Health Study participants $(p=0.039)$. No differences in height were observed for either males or females. The percent of participants with an undesirable BMI was higher among Seminar females $(p=0.011)$. While BMI did not differ for the groups, the average BMI of Seminar males and females was considered overweight, while Health Study participants were classified as lean.

Table 1. Health measures.

\begin{tabular}{|c|c|c|c|c|c|c|c|c|}
\hline & \multicolumn{4}{|c|}{ Health Study ( $n=43$ Male, 148 Female) } & \multicolumn{4}{|c|}{ Seminar ( $n=30$ Male, 40 Female) } \\
\hline & Baseline & Follow-Up & Absolute Change & Percent Change & Baseline & Follow-Up & Absolute Change & Percent Change \\
\hline \multicolumn{9}{|c|}{ Systolic BP (mmHg) } \\
\hline Male ${ }^{\mathrm{d}}$ & $124.0 \pm 2.4$ & $128.3 \pm 1.6$ & $4.3 \pm 2.2$ & $5.6 \pm 3.2 \%$ & $129.3 \pm 2.1$ & $134.7 \pm 2.5$ & $5.4 \pm 3.3$ & $5.0 \pm 2.7 \%$ \\
\hline Female ${ }^{a, c, d}$ & $114.9 \pm 0.8$ & $118.3 \pm 0.9$ & $3.4 \pm 0.9$ & $3.4 \pm 0.8 \%$ & $121.2 \pm 2.4$ & $122.8 \pm 2.2$ & $1.6 \pm 2.0$ & $2.1 \pm 1.7 \%$ \\
\hline \multicolumn{9}{|c|}{ Diastolic BP (mmHg) } \\
\hline Male ${ }^{c, d}$ & $71.9 \pm 1.7$ & $71.7 \pm 1.8$ & $-0.2 \pm 2.0$ & $0.9 \pm 2.6 \%$ & $79.4 \pm 1.8$ & $81.4 \pm 1.7$ & $2.4 \pm 2.2$ & $4.5 \pm 2.7 \%$ \\
\hline Female ${ }^{c, d}$ & $69.5 \pm 0.6$ & $70.4 \pm 0.9$ & $0.9 \pm 1.0$ & $2.0 \pm 1.4 \%$ & $79.4 \pm 1.8$ & $81.7 \pm 1.3$ & $2.2 \pm 1.8$ & $4.4 \pm 2.6 \%$ \\
\hline \multicolumn{9}{|c|}{ Undesirable BP } \\
\hline Male $^{\mathrm{c}}$ & $69.8 \%$ & $74.4 \%$ & $4.6 \%$ & $6.6 \%$ & $93.3 \%$ & $93.3 \%$ & $0.0 \%$ & $0.0 \%$ \\
\hline Female ${ }^{a, c, d}$ & $34.5 \%$ & $46.6 \%$ & $12.2 \%$ & $34.8 \%$ & $64.1 \%$ & $74.4 \%$ & $10.3 \%$ & $16.1 \%$ \\
\hline \multicolumn{9}{|c|}{ Height $(\mathrm{cm})$} \\
\hline Male & $177.6 \pm 0.9$ & $177.9 \pm 1.0$ & $0.3 \pm 0.1$ & $0.2 \pm 0.1 \%$ & $178.7 \pm 1.4$ & $179.1 \pm 1.4$ & $0.4 \pm 0.3$ & $0.2 \pm 0.2 \%$ \\
\hline Female & $163.2 \pm 0.5$ & $163.4 \pm 0.5$ & $0.2 \pm 0.1$ & $0.1 \pm 0.0 \%$ & $164.8 \pm 0.8$ & $165.3 \pm 0.8$ & $0.4 \pm 0.1$ & $0.2 \pm 0.1 \%$ \\
\hline \multicolumn{9}{|c|}{ Weight (kg) } \\
\hline Male ${ }^{a, b}$ & $74.2 \pm 2.1$ & $75.8 \pm 2.1$ & $1.6 \pm 0.3$ & $2.2 \pm 0.4 \%$ & $80.4 \pm 3.8$ & $82.5 \pm 3.8$ & $2.0 \pm 0.6$ & $2.7 \pm 0.7 \%$ \\
\hline Female ${ }^{a, b, c}$ & $62.7 \pm 1.3$ & $64.1 \pm 1.3$ & $1.4 \pm 0.2$ & $2.2 \pm 0.3 \%$ & $70.5 \pm 3.4$ & $71.7 \pm 3.5$ & $0.9 \pm 0.3$ & $1.5 \pm 0.6 \%$ \\
\hline \multicolumn{9}{|c|}{ BMI $\left(\mathrm{kg} / \mathrm{m}^{2}\right)$} \\
\hline Male $a, b$ & $23.5 \pm 0.6$ & $23.9 \pm 0.6$ & $0.4 \pm 0.1$ & $1.5 \pm 0.4 \%$ & $25.1 \pm 1.1$ & $25.6 \pm 1.1$ & $0.5 \pm 0.2$ & $2.2 \pm 0.8 \%$ \\
\hline Female $^{a}$ & $23.5 \pm 0.4$ & $23.9 \pm 0.4$ & $0.4 \pm 0.1$ & $1.9 \pm 0.3 \%$ & $26.1 \pm 1.3$ & $26.2 \pm 1.2$ & $0.2 \pm 0.2$ & $0.9 \pm 0.7 \%$ \\
\hline \multicolumn{9}{|c|}{ Undesirable BMI } \\
\hline Male & $27.9 \%$ & $30.2 \%$ & $2.3 \%$ & $8.2 \%$ & $37.5 \%$ & $40.6 \%$ & $3.1 \%$ & $8.3 \%$ \\
\hline Female ${ }^{c, d}$ & $21.6 \%$ & $26.4 \%$ & $4.8 \%$ & $22.2 \%$ & $41.5 \%$ & $41.5 \%$ & $0.0 \%$ & $0.0 \%$ \\
\hline \multicolumn{9}{|c|}{ Body Fat (\%) } \\
\hline Male ${ }^{\mathrm{b}}$ & $15.2 \pm 1.2$ & $16.6 \pm 1.0$ & $1.4 \pm 0.4$ & $15.7 \pm 3.4 \%$ & $16.5 \pm 1.6$ & $18.0 \pm 1.7$ & $1.6 \pm 0.5$ & $13.3 \pm 4.8 \%$ \\
\hline Female $^{a, b}$ & $28.5 \pm 0.7$ & $29.5 \pm 0.6$ & $1.1 \pm 0.3$ & $8.7 \pm 4.5 \%$ & $30.1 \pm 1.7$ & $31.7 \pm 1.7$ & $1.6 \pm 0.4$ & $7.9 \pm 2.6 \%$ \\
\hline
\end{tabular}

All values are means \pm standard error of the mean. Abbreviations: $B P=$ blood pressure, $\mathrm{BMI}=$ body mass index. Absolute change $=$ follow-up - baseline. Percent change $=$ absolute change $/$ baseline. Classifications: Undesirable $\mathrm{BP}=$ systolic $\geq 120 \mathrm{mmHg}$ and/or diastolic $\geq 80 \mathrm{mmHg}$. Undesirable BMI $\geq 25 \mathrm{~kg} / \mathrm{m}^{2}$. Significant differences $(p<0.05)$ are indicated by superscripts: ${ }^{\mathrm{a}}$ for absolute changes over time in the Health Study group, ${ }^{\mathrm{b}}$ for absolute changes over time in the Seminar group, ${ }^{c}$ for differences at baseline between groups, and ${ }^{d}$ for difference at follow-up between groups.

At follow-up (Table 1), both systolic and diastolic BP were higher among Seminar participants of both sexes ( $p \leq 0.027$ for all). The percentage of participants with undesirable BP was higher in female Seminar participants $(p=0.003)$. The percentage of participants with undesirable BMI was higher among Seminar females $(p=0.048)$.

In terms of absolute changes over time, males from both groups experienced an increase in weight and BMI, while males in the Seminar group also experienced an increase in \%BF (Table 1; $p \leq 0.009$ for all). Females in both groups experienced increases in weight and \%BF ( $p \leq 0.029$ for all). 
BMI increased in Health Study females $(p<0.001)$. Females in the Health Study group experienced increases in systolic BP and in the percentage of participants with undesirable BP ( $p \leq 0.003$ for both). However, the percent change difference in these values did not differ between the groups.

\subsection{Differences in Dietary Behaviors}

In terms of dietary behavior at baseline, male Seminar participants $(N=29)$ indicated less-frequent added fat consumption compared to Health Study males $(N=43 ; p=0.035$; Table 2$)$. Seminar females $(N=37)$ reported less frequent fruit and higher added fat consumption than Health Study females ( $N=148, p \leq 0.004$ for both). No differences in total diet scores were observed at baseline, although Seminar participants had less-desirable scores.

At follow-up, Seminar males reported more frequent consumption of sweetened beverages compared to Health Study males $(p=0.022)$. While Seminar females reported less-frequent consumption of sweet snacks, consumption of lean protein was lower and added fat use was higher than Health Study females at follow-up ( $p \leq 0.031$ for all). Total diet score at follow-up was lower (more desirable) among Health Study females $(p=0.040)$; compared to baseline, female Seminar participants' total diet scores worsened while Health Study participants' scores improved, but the change in total diet score did not differ between groups.

Table 2. Diet behavior.

\begin{tabular}{|c|c|c|c|c|c|c|c|c|c|c|c|c|}
\hline & \multicolumn{6}{|c|}{ Health Study } & \multicolumn{6}{|c|}{ Seminar } \\
\hline & \multicolumn{2}{|c|}{ Most Healthful } & \multicolumn{2}{|c|}{ Somewhat Healthful } & \multicolumn{2}{|c|}{ Least Healthful } & \multicolumn{2}{|c|}{ Most Healthful } & \multicolumn{2}{|c|}{ Somewhat Healthful } & \multicolumn{2}{|c|}{ Least Healthful } \\
\hline & Base-line & Follow-up & Base-line & Follow-up & Base-line & Follow-up & Base-line & Follow-up & Base-line & Follow-up & Base-line & $\overline{\text { Follow-up }}$ \\
\hline \multicolumn{13}{|c|}{ How many times a week did you eat fast food meals or snacks? } \\
\hline Male & 30.2 & 34.9 & 48.8 & 55.8 & 20.9 & 9.3 & 24.1 & 43.5 & 58.6 & 43.5 & 17.2 & 13.0 \\
\hline Female $^{\text {a }}$ & 21.6 & 34.5 & 52.7 & 54.7 & 25.7 & 10.8 & 27.0 & 34.4 & 59.5 & 50.0 & 13.5 & 15.6 \\
\hline \multicolumn{13}{|c|}{ How many servings of fruit did you eat each day? } \\
\hline Male & 4.7 & 0.0 & 53.5 & 51.2 & 41.9 & 48.8 & 6.9 & 4.3 & 34.5 & 52.2 & 58.6 & 43.5 \\
\hline Female ${ }^{a, b}$ & 10.2 & 3.4 & 41.5 & 41.9 & 48.3 & 54.7 & 0.0 & 0.0 & 24.3 & 28.1 & 75.7 & 71.9 \\
\hline \multicolumn{13}{|c|}{ How many servings of vegetables did you eat each day? } \\
\hline & \multicolumn{2}{|c|}{$5+$} & & & & & & & & & & \\
\hline Male & 9.3 & 7.0 & 41.9 & 39.5 & 48.8 & 53.5 & 10.3 & 8.7 & 17.0 & 43.5 & 72.4 & 47.8 \\
\hline Female & 2.7 & 5.4 & 41.2 & 33.1 & 56.1 & 61.5 & 0.0 & 0.0 & 35.1 & 28.1 & 64.9 & 71.9 \\
\hline & & & How man & times a weel & did you eat & eans (like pi & to or black & ans), chicke & or fish? & & & \\
\hline & & & & & & & & & & & & \\
\hline Male & 72.1 & 58.1 & 20.9 & 34.9 & 7.0 & 7.0 & 55.2 & 56.5 & 34.5 & 26.1 & 10.3 & 17.4 \\
\hline Female $^{c}$ & 60.1 & 52.0 & 29.7 & 37.2 & 10.1 & 10.8 & 45.9 & 28.1 & 32.4 & 43.8 & 21.6 & 28.1 \\
\hline & & & How $\mathrm{m}$ & hy times a w & ek did you & t regular sna & c chips or $\mathrm{c}$ & ckers (not lo & -fat)? & & & \\
\hline & & & & & & & & & & & & \\
\hline Male & 55.8 & 69.8 & 34.9 & 20.9 & 9.3 & 9.3 & 44.8 & 52.2 & 44.8 & 43.5 & 10.3 & 4.3 \\
\hline Female $^{c}$ & 52.0 & 52.7 & 39.9 & 41.2 & 8.1 & 6.1 & 40.5 & 34.4 & 45.9 & 40.6 & 13.5 & 25.0 \\
\hline & & & How mar & times a wee & did you ea & lesserts and & her sweets & lot the low-f & kind)? & & & \\
\hline & & & & & & & & & & & & \\
\hline Male & 23.3 & 20.9 & 51.2 & 58.1 & 25.6 & 20.9 & 24.1 & 39.1 & 72.4 & 43.5 & 3.4 & 17.4 \\
\hline
\end{tabular}

All values are percentages. Significant differences $(p<0.05)$ are indicated by superscripts: ${ }^{a}$ for changes over time in the Health Study group, ${ }^{b}$ for differences at baseline between groups, and ${ }^{c}$ for difference at follow-up between groups. 


\subsection{Differences in Alcohol Consumption Patterns}

At baseline, the pattern of responses differed between males in terms of amount consumed per day and binge drinking behaviors, with Seminar participants $(N=32)$ consuming more than Health Study participants $(N=43$; Table 3). Female Seminar participants $(N=37)$ reported drinking more per day and more frequent binge drinking behaviors than Health Study participants $(N=148)$. At follow-up, male Seminar participants consumed alcohol more often, consumed more per day, and more frequently engaged in binge drinking behaviors than Health Study participants. Female Seminar students consumed more alcohol per day and engaged in more frequent binge drinking behaviors than Health Study participants. Drinking behaviors in males did not change over time. Health Study females increased the frequency of their drinking $(p=0.003)$ and binge drinking behaviors over time $(p=0.046)$. In terms of overall AUDIT-C scores, no differences were observed between the groups at either baseline or follow-up, although Seminar students had higher scores for all groups and at all time points. Only Health Study females' total score increased over time $(p=0.008)$, but the follow-up score was lower than the baseline Seminar female score. Change in total alcohol score did not differ between any of the groups.

Table 3. Alcohol.

\begin{tabular}{|c|c|c|c|c|c|c|c|}
\hline \multicolumn{8}{|c|}{ How Often Do You Have a Drink Containing Alcohol? (Frequency) } \\
\hline Male & & Never & Monthly or less & 2-4 times per month & 2-3 times per week & $4+$ times per week & $p$-value \\
\hline Health Study & Baseline & 58.1 & 27.9 & 11.6 & 2.3 & 0.0 & N.S. \\
\hline Seminar & Baseline & 44.8 & 20.7 & 27.6 & 6.9 & 0.0 & \\
\hline Health Study & Follow-Up & 62.8 & 20.9 & 16.3 & 0.0 & 0.0 & $p=0.049$ \\
\hline Seminar & Follow-Up & 45.5 & 9.1 & 36.4 & 9.1 & 0.0 & \\
\hline \multicolumn{8}{|l|}{ Female $^{a}$} \\
\hline Health Study & Baseline & 56.1 & 27.0 & 16.2 & 0.7 & 0.0 & N.S. \\
\hline Seminar & Baseline & 48.6 & 29.7 & 13.5 & 8.1 & 0.0 & \\
\hline Health Study & Follow-Up & 49.3 & 26.4 & 18.9 & 4.1 & 1.4 & N.S. \\
\hline Seminar & Follow-Up & 39.4 & 30.3 & 27.3 & 0.0 & 3.0 & \\
\hline \multicolumn{8}{|c|}{ How many standard drinks containing alcohol do you have on a typical day? (Amount) } \\
\hline Male & & 1 or 2 & 3 or 4 & 5 or 6 & 7 to 9 & $10+$ & \\
\hline Health Study & Baseline & 76.7 & 16.3 & 7.0 & 0.0 & 0.0 & $p<0.001$ \\
\hline Seminar & Baseline & 25.0 & 18.8 & 37.5 & 18.8 & 0.0 & \\
\hline Health Study & Follow-Up & 74.4 & 14.0 & 11.6 & 0.0 & 0.0 & $p=0.023$ \\
\hline Seminar & Follow-Up & 18.2 & 18.2 & 36.4 & 18.2 & 9.1 & \\
\hline \multicolumn{8}{|l|}{ Female } \\
\hline Health Study & Baseline & 83.8 & 10.8 & 2.7 & 1.4 & 1.4 & $p<0.001$ \\
\hline Seminar & Baseline & 63.2 & 15.8 & 15.8 & 5.3 & 0.0 & \\
\hline Health Study & Follow-Up & 79.7 & 11.5 & 5.4 & 3.4 & 0.0 & $p=0.022$ \\
\hline Seminar & Follow-Up & 55.0 & 30.0 & 15.0 & 0.0 & 0.0 & \\
\hline \multicolumn{8}{|c|}{ How often do you have six or more drinks on one occasion? (Binge) } \\
\hline Male & & Never & Less than monthly & Monthly & Weekly & Daily or almost daily & \\
\hline Health Study & Baseline & 74.4 & 18.6 & 4.7 & 2.3 & 0.0 & $p<0.001$ \\
\hline Seminar & Baseline & 25.0 & 31.3 & 25.0 & 18.8 & 0.0 & \\
\hline Health Study & Follow-Up & 81.4 & 9.3 & 7.0 & 2.3 & 0.0 & $p<0.001$ \\
\hline Seminar & Follow-Up & 9.1 & 36.4 & 45.5 & 9.1 & 0.0 & \\
\hline \multicolumn{8}{|l|}{ Female $^{a}$} \\
\hline Health Study & Baseline & 87.2 & 8.8 & 2.0 & 2.0 & 0.0 & $p<0.001$ \\
\hline Seminar & Baseline & 42.1 & 47.4 & 0.0 & 10.5 & 0.0 & \\
\hline Health Study & Follow-Up & 82.4 & 9.5 & 6.1 & 2.0 & 0.0 & $p<0.001$ \\
\hline Seminar & Follow-Up & 35.0 & 50.0 & 10.0 & 5.0 & 0.0 & \\
\hline \multicolumn{8}{|c|}{ Total AUDIT-C Score } \\
\hline Male & & & & Female $^{a}$ & & & \\
\hline Health Study & Baseline & $1.2 \pm 0.3$ & N.S. & Health Study & Baseline & $1.1 \pm 0.2$ & N.S. \\
\hline Seminar & Baseline & $2.6 \pm 0.6$ & & Seminar & Baseline & $1.5 \pm 0.3$ & \\
\hline Health Study & Follow-Up & $1.2 \pm 0.3$ & N.S. & Health Study & Follow-Up & $1.4 \pm 0.2$ & N.S. \\
\hline Seminar & Follow-Up & $2.8 \pm 0.7$ & & Seminar & Follow-Up & $1.9 \pm 0.4$ & \\
\hline
\end{tabular}

\section{Discussion}

This study compared the health measures and behaviors of participants who self-selected into a health-focused research study to students in an introductory seminar-style class. Identifying the 
magnitude of the effect of selection bias is difficult because the measurement of non-participants typically does not occur [35]. When differences in health measures and health behaviors were observed at baseline, these differences were almost always more undesirable among the Seminar participants, suggesting that participants who self-select into health-related studies are likely healthier than the general population. These findings agree with previous work that observed that participants who participated in a healthy aging study [14], a health check study [12], and an exercise study [11] were in better physical shape than those individuals who did not participate.

At follow-up, participants from the Health Study group had more desirable health measures than Seminar group participants. Health Study participants showed more evidence of improved dietary behaviors. Female Health Study participants did increase their use of alcohol over time; still, this increase was lower than Seminar participants' use at baseline. While participants in the Seminar group might not have been as focused on their health as the participants who volunteered for the Health Study, participants in the Seminar group still had to agree to share their data, and we were unable to assess if the $20 \%$ of Seminar students who did not participate were significantly less healthy than those who did. Others have reported that individuals with increased adiposity as measured by waist-to-hip ratio were less likely to participate in follow-up study visits [16], and decreased response rates to an invitation to participate in a follow-up health examination were associated with higher initial BMI [18]. It is possible that if these data were available, it would result in further separation of the results between the groups, reflecting an even greater bias. Because students who enter their first year of university already classified as overweight or obese are at higher risk for developing chronic diseases [10], a better understanding of the magnitude of the health issues facing university students is of paramount importance.

In order to achieve samples that are less biased and more representative of the general university population, adequate compensation for participants may motivate more students who are not as health-conscious or healthy to participate. One report reviewed a number of studies that assessed participant motivation to enroll in health studies and noted that financial compensation was either the most important or a considerably important factor in determining participation [26]. How much participants should be paid is unknown. One study examined health study participant payment between 1997 and 1998, and found that participants were paid, on average, \$9.50 per hour [21]. Adjusting for inflation using the U.S. Bureau of Labor Statistics Consumer Price Index Inflation Calculator [36], an equivalent payment in January 2016 would be $\$ 13.93$ per hour. Given that our Health Study visits lasted less than $30 \mathrm{~min}$, our payment of $\$ 5$ or a spirit item (water bottle, T-shirt) did not exceed these suggestions. This likely means that our Health Study participants were very interested in monitoring their health over the course of the semester, as the compensation for participating was not especially generous. A variety of other recent (since 2012) studies have provided compensation in a variety of ways. Examples include: through course credit [37]; by allowing participants to choose $3 \mathrm{~h}$ of research credit or $\$ 20$ per visit (equivalent of $\$ 6.66$ per research credit hour) [38]; or did not report how participants were compensated [39]. Adequate compensation for these studies is an area that requires further examination.

There were distinct differences between groups at baseline and follow-up, differences in the degree of change between the time points were not routinely observed for absolute changes, and no percent change differences were noted for health measures between the groups. This was surprising, as there are a number of examples where self-selection has influenced study outcomes. For example, self-selection explained a significant portion of the relationship between lower BMI and the duration and rate of walking over a 7-10 year period [40]. That is, individuals who were lean at the beginning of the study chose to be more active than their heavier counterparts. Similarly, pre-exercise BMI was responsible for the relationship between fitness level, measured by running speed for a $10 \mathrm{~km}$ race and weekly running distance, and current BMI [41]. Discrepancies in the results of the present study compared to the results of these other studies might be attributed to the differences in the composition of the study populations (e.g., age, newly adjusting to the university environment, etc.). 
Still, the results from the present study suggest that, regardless of the motivation to self-select into a health-related study-which might or might not include an interest in one's health-participants still experienced negative outcomes regarding anthropometric measures, and these changes occurred to the same degree as non-Health Study participants. It appears that motivation for study participation does not substantively influence changes in health outcomes in first-year university students.

\section{Strengths and Limitations}

To our knowledge, this is the first attempt to assess whether self-selected volunteers who participate in first-year university student health studies differ significantly from the larger student population. While the repeated measures design increases the power to detect differences, sample sizes were still small, and the 4-month duration might not be long enough to see all changes. Self-reported diet and alcohol measures are subject to under-reporting, and the small pool of male participants means that generalization of results should be made with caution when comparing between groups. While Seminar participants did not deliberately decide to participate in a health study, they were able to decide whether or not they would share their data, so the differences we observed likely underestimate true differences based on the previously cited work suggesting differences between participants and non-participants.

\section{Conclusions}

Based on these results, students who self-select into health-related studies typically start off and end up with better health indicators but experience changes similar to those students who do not enroll in these types of studies. We conclude that health studies among university students that use participants who self-select likely underestimate the prevalence of undesirable health measures and behaviors, but that these studies likely accurately reflect changes that occur over time in the larger first-year university student population.

Acknowledgments: This work was funded by the DuPont Nutrition \& Health/Academy of Nutrition \& Dietetics Research Dietetic Practice Group Early Career Research Scientist Pilot Grant Program (M.-J.L., R.M.T.), the Medical Mutual/Bowling Green State University Center of Excellence for Health \& Wellness across the Lifespan's Health \& Wellness Innovation \& Collaboration Grant Program (M.-J.L.), and the Bowling Green State University College of Education \& Human Development's Research Development Council Grant Program (M.-J.L., A.L.M.).

Author Contributions: M.-J.L., A.L.M., R.M.T. conceived and designed the experiment; A.P.C., M.-J.L., A.L.M., C.A.Y., and R.M.T. performed the experiment; M.-J.L., A.P.C., R.M.T. analyzed the data; M.-J.L. and R.M.T. wrote the paper; all authors contributed to the editing and revision of the paper.

Conflicts of Interest: The authors declare no conflict of interest.

\section{References}

1. Fedewa, M.V.; Das, B.M.; Evans, E.M.; Dishman, R.K. Change in weight and adiposity in college students: A systematic review and meta-analysis. Am. J. Prev. Med. 2014, 47, 641-652. [CrossRef] [PubMed]

2. Vella-Zarb, R.A.; Elgar, F.J. Predicting the 'freshman 15': Environmental and psychological predictors of weight gain in first-year university students. Health Educ. J. 2010, 69, 321-332. [CrossRef]

3. Zagorsky, J.L.; Smith, P.K. The freshman 15: A critical time for obesity intervention or media myth? Soc. Sci. Q. 2011, 92, 1389-1407. [CrossRef]

4. Wengreen, H.J.; Moncur, C. Change in diet, physical activity, and body weight among young-adults during the transition from high school to college. Nutr. J. 2009, 8, 32. [CrossRef] [PubMed]

5. Pope, L.; Harvey-Berino, J. Burn and earn: A randomized controlled trial incentivizing exercise during fall semester for college first-year students. Prev. Med. 2013, 56, 197-201. [CrossRef] [PubMed]

6. Gropper, S.S.; Newton, A.; Harrington, P.; Simmons, K.P.; Connell, L.J.; Ulrich, P. Body composition changes during the first two years of university. Prev. Med. 2011, 52, 20-22. [CrossRef] [PubMed]

7. Gropper, S.S.; Simmons, K.P.; Connell, L.J.; Ulrich, P.V. Weight and body composition changes during the first three years of college. J. Obes. 2012, 2012, 634048. [CrossRef] [PubMed] 
8. Gropper, S.S.; Simmons, K.P.; Connell, L.J.; Ulrich, P.V. Changes in body weight, composition, and shape: A 4-year study of college students. Appl. Physiol. Nutr. Metab. 2012, 37, 1118-1123. [CrossRef] [PubMed]

9. Lloyd-Richardson, E.E.; Bailey, S.; Fava, J.L.; Wing, R.; Network, T.E.R. A prospective study of weight gain during the college freshman and sophomore years. Prev. Med. 2009, 48, 256-261. [CrossRef] [PubMed]

10. Hajhosseini, L.; Holmes, T.; Mohamadi, P.; Goudarzi, V.; McProud, L.; Hollenbeck, C.B. Changes in body weight, body composition and resting metabolic rate (RMR) in first-year university freshmen students. J. Am. Coll. Nutr. 2006, 25, 123-127. [CrossRef] [PubMed]

11. De Souto Barreto, P.; Ferrandez, A.-M.; Saliba-Serre, B. Are older adults who volunteer to participate in an exercise study fitter and healthier than nonvolunteers? The participation bias of the study population. J. Phys. Act. Health 2013, 10, 359-367. [CrossRef] [PubMed]

12. Bender, A.M.; Jørgensen, T.; Pisinger, C. Is self-selection the main driver of positive interpretations of general health checks? The Inter99 randomized trial. Prev. Med. 2015, 81, 42-48. [CrossRef] [PubMed]

13. Lissner, L.; Heitmann, B.L.; Bengtsson, C. Population studies of diet and obesity. Br. J. Nutr. 2000, 83, S21-S24. [CrossRef] [PubMed]

14. Van Heuvelen, M.J.; Hochstenbach, J.B.; Brouwer, W.H.; de Greef, M.H.; Zijlstra, G.A.; van Jaarsveld, E.; Kempen, G.I.; van Sonderen, E.; Ormel, J.; Mulder, T. Differences between participants and non-participants in an RCT on physical activity and psychological interventions for older persons. Aging Clin. Exp. Res. 2005, 17, 236-245. [CrossRef] [PubMed]

15. Heckman, J.J. Sample selection bias as a specification error. Econometrica 1979, 47, 153-161. [CrossRef]

16. Heckman, J.J. Selection bias and self-selection. In Econometrics; Eatwell, J., Milgate, M., Newman, P., Eds.; The New Palgrave: London, UK, 1990; pp. 201-224.

17. Heckman, J.J. Selection Bias and Self-Selection. In Microeconometrics; Durlauf, S.N., Blume, L.E., Eds.; The New Palgrave Economics Collection; Palgrave Macmillan: London, UK, 2010.

18. Bengtsson, C.; Gredmark, T.; Hallberg, L.; Hällstrüm, T.; Isaksson, B.; Lapidus, L.; Lindquist, O.; Lindstedt, S.; Lurie, M.; Nystrüm, E. The population study of women in Gothenburg 1980-81-The third phase of a longitudinal study. Scand. J. Soc. Med. 1989, 17, 141-145. [CrossRef] [PubMed]

19. Ortner Hadžiabdić, M.; Mucalo, I.; Hrabač, P.; Matić, T.; Rahelić, D.; Božikov, V. Factors predictive of drop-out and weight loss success in weight management of obese patients. J. Hum. Nutr. Diet. 2015, 28, 24-32. [CrossRef] [PubMed]

20. Sonne-Holm, S.; Sørensen, T.I.; Jensen, G.; Schnohr, P. Influence of fatness, intelligence, education and sociodemographic factors on response rate in a health survey. J. Epidemiol. Community Health 1989, 43, 369-374. [CrossRef] [PubMed]

21. Latterman, J.; Merz, J.F. How much are subjects paid to participate in research? Am. J. Bioeth. 2001, 1, 45-46. [CrossRef] [PubMed]

22. Leentjens, A.F.; Levenson, J.L. Ethical issues concerning the recruitment of university students as research subjects. J. Psychosom. Res. 2013, 75, 394-398. [CrossRef] [PubMed]

23. Russell, M.L.; Moralejo, D.G.; Burgess, E.D. Paying research subjects: Participants' perspectives. J. Med. Ethics 2000, 26, 126-130. [CrossRef] [PubMed]

24. Hassar, M.; Pocelinko, R.; Weintraub, M.; Nelson, D.; Thomas, G.; Lasagna, L. Free-living volunteer's motivations and attitudes toward pharmacologic studies in man. Clin. Pharmacol. Ther. 1977, 21, 515-519. [CrossRef] [PubMed]

25. Perez, M.; Ohrt, T.K.; Bruening, A.B. The effects of different recruitment and incentive strategies for body acceptance programs on college women. Eat. Disord. 2016, 24, 383-392. [CrossRef] [PubMed]

26. Tishler, C.L.; Bartholomae, S. The recruitment of normal healthy volunteers: A review of the literature on the use of financial incentives. J. Clin. Pharmacol. 2002, 42, 365-375. [CrossRef] [PubMed]

27. Paxton, A.E.; Strycker, L.A.; Toobert, D.J.; Ammerman, A.S.; Glasgow, R.E. Starting the Conversation: Performance of a brief dietary assessment and intervention tool for health professionals. Am. J. Prev. Med. 2011, 40, 67-71. [CrossRef] [PubMed]

28. Miller, P.B.; Anthony, D.; Yarrish, K.K. Exploration of healthy eating education and consumption of various foods of college students in a small liberal arts college. Contemp. Issues Educ. Res. Online 2013, 6, 67. [CrossRef]

29. Bergeron, N.; Al-Saiegh, S.; Ip, E.J. An analysis of California pharmacy and medical students' dietary and lifestyle practices. Am. J. Pharm. Educ. 2017, 81, 5956. [CrossRef] [PubMed] 
30. Bush, K.; Kivlahan, D.R.; McDonell, M.B.; Fihn, S.D.; Bradley, K.A. The AUDIT alcohol consumption questions (AUDIT-C): An effective brief screening test for problem drinking. Arch. Intern. Med. 1998, 158, 1789-1795. [CrossRef] [PubMed]

31. Kokotailo, P.K.; Egan, J.; Gangnon, R.; Brown, D.; Mundt, M.; Fleming, M. Validity of the alcohol use disorders identification test in college students. Alcohol. Clin. Exp. Res. 2004, 28, 914-920. [CrossRef] [PubMed]

32. Wells, J.C.K. Sexual dimorphism of body composition. Best Pract. Res. Clin. Endocrinol. Metab. 2007, 21, 415-430. [CrossRef] [PubMed]

33. Cluskey, M.; Grobe, D. College weight gain and behavior transitions: Male and female differences. J. Am. Diet. Assoc. 2009, 109, 325-329. [CrossRef] [PubMed]

34. Reckelhoff, J.F. Gender differences in the regulation of blood pressure. Hypertension 2001, 37, 1199-1208. [CrossRef] [PubMed]

35. Khazaal, Y.; Van Singer, M.; Chatton, A.; Achab, S.; Zullino, D.; Rothen, S.; Khan, R.; Billieux, J.; Thorens, G. Does self-selection affect samples' representativeness in online surveys? An investigation in online video game research. J. Med. Internet Res. 2014, 16, e164. [CrossRef] [PubMed]

36. United States Department of Labor, Bureau of Labor Statitics CPI Inflation Calculator. Available online: https:/ / data.bls.gov/cgi-bin/cpicalc.pl (accessed on 19 February 2018).

37. Culnan, E.; Kloss, J.D.; Grandner, M. A prospective study of weight gain associated with chronotype among college freshmen. Chronobiol. Int. 2013, 30, 682-690. [CrossRef] [PubMed]

38. Webb, J.B. Evaluating race/ethnicity in moderating baseline cardiometabolic risk and body composition changes in North Carolina first-year college women. Women Health 2012, 52, 553-569. [CrossRef] [PubMed]

39. Gillen, M.M.; Lefkowitz, E.S. The 'freshman 15': Trends and predictors in a sample of multiethnic men and women. Eat. Behav. 2011, 12, 261-266. [CrossRef] [PubMed]

40. Williams, P.T. Self-selection contributes significantly to the lower adiposity of faster, longer-distanced, male and female walkers. Int. J. Obes. 2007, 31, 652-662. [CrossRef] [PubMed]

41. Williams, P.T. Self-selection accounts for inverse association between weight and cardiorespiratory fitness. Obesity 2008, 16, 102-106. [CrossRef] [PubMed]

(C) 2018 by the authors. Licensee MDPI, Basel, Switzerland. This article is an open access article distributed under the terms and conditions of the Creative Commons Attribution (CC BY) license (http:/ / creativecommons.org/licenses/by/4.0/). 